\title{
Chlamydia trachomatis infection during pregnancy associated with preterm delivery: a population-based prospective cohort study
}

\author{
G. Ingrid J. G. Rours • Liesbeth Duijts • Henriette A. Moll $\cdot$ Lidia R. Arends $\cdot$ Ronald de Groot \\ Vincent W. Jaddoe - Albert Hofman • Eric A. P. Steegers · Johan P. Mackenbach • Alewijn Ott • \\ Hendrina F. M. Willemse $\cdot$ Elizabeth A. E. van der Zwaan • Roel P. Verkooijen $\cdot$ Henri A. Verbrugh
}

Received: 25 November 2010/Accepted: 15 April 2011/Published online: 3 May 2011

(c) The Author(s) 2011. This article is published with open access at Springerlink.com

\begin{abstract}
Chlamydia trachomatis infection is the most prevalent bacterial sexually transmitted infection and may influence pregnancy outcome. This study was conducted to assess the effect of chlamydial infection during pregnancy on premature delivery and birthweight. Pregnant women attending a participating midwifery practice or antenatal clinic between February 2003 and January 2005 were eligible for the study. From 4,055 women self-administered questionnaires and urine samples, tested by PCR, were analysed for $C$. trachomatis infection. Pregnancy outcomes were obtained from midwives and hospital registries. Gestational ages and birthweights were analysed for 3,913 newborns. The C. trachomatis prevalence was $3.9 \%$, but varied by age and socio-economic background. Chlamydial infection was, after adjustment for potential confounders, associated with preterm delivery before 32 weeks (OR 4.35 [95\% CI 1.3, 15.2]) and 35 weeks gestation (OR 2.66 [95\% CI 1.1, 6.5]), but not with low birthweight. Of all deliveries
\end{abstract}

G. Ingrid J.G. Rours and Liesbeth Duijts these authors contributed equally to this study.

G. I. J. G. Rours $(\bowtie) \cdot$ L. Duijts · L. R. Arends · V. W. Jaddoe The Generation R Study group, Erasmus University Medical Centre, Rotterdam, The Netherlands

e-mail: rours@mac.com

G. I. J. G. Rours · L. Duijts · H. A. Moll · R. de Groot

V. W. Jaddoe

Department of Pediatrics, Erasmus University Medical Centre, Rotterdam, The Netherlands

G. I. J. G. Rours - A. Ott - H. F. M. Willemse

E. A. E. van der Zwaan - R. P. Verkooijen - H. A. Verbrugh

Department of Medical Microbiology and Infectious Diseases,

Erasmus University Medical Centre, Rotterdam,

The Netherlands before 32 weeks and 35 weeks gestation $14.9 \%$ [95\% CI 4.5, 39.5] and $7.4 \%$ [95\% CI 2.5, 20.1] was attributable to C. trachomatis infection. Chlamydia trachomatis infection contributes significantly to early premature delivery and should be considered a public health problem, especially in young women and others at increased risk of $C$. trachomatis infection.

Keywords Chlamydia trachomatis · Pregnancy ·

Prematurity · Prevalence · Risk factors · Low birthweight

\section{Introduction}

Chlamydia trachomatis is an important cause of sexually transmitted infections (STIs) in women, which may lead to pelvic inflammatory disease, tubal infertility, ectopic pregnancy, and chronic abdominal pain [1-4]. Chlamydial infection during pregnancy may in addition influence pregnancy outcomes leading to premature rupture of membranes, prematurity, low birthweight and perinatal

L. R. Arends · V. W. Jaddoe · A. Hofman

Department of Epidemiology, Erasmus University Medical

Centre, Rotterdam, The Netherlands

E. A. P. Steegers

Department of Obstetrics and Gynaecology, Erasmus University

Medical Centre, Rotterdam, The Netherlands

J. P. Mackenbach

Department of Public Health, Erasmus University Medical

Centre, Rotterdam, The Netherlands

A. Ott

Laboratory for Infectious Diseases, Groninge, The Netherlands 
mortality, and cause neonatal conjunctival and respiratory infection [5-7]. The literature regarding the detrimental effects of $C$. trachomatis infection on pregnancy outcome, however, yields conflicting results that seem primarily due to differences in study design, population and microbiological tests employed [8-24].

Screening for $C$. trachomatis in pregnant women has revealed prevalence rates varying from 0 to $37 \%$ and various associated risk factors for infection including in particular age and socio-economic status [25-27].

In the Netherlands, a chlamydial prevalence of $2.5 \%$ was reported in women [28]. However, prenatal screening for $C$. trachomatis is not routine obstetrical practice in the Netherlands and data on pregnant women and pregnancy outcome are lacking.

The objective of this study was to assess the prevalence of $C$. trachomatis infection in pregnant women and to investigate the association of chlamydial infection with the risks of preterm delivery and low birthweight or being small for gestational age.

\section{Methods}

\section{Design}

This Chlamydia trachomatis study was embedded in the Generation R Study, which is a population-based, noninterventional, prospective cohort study designed to identify early environmental and genetic determinants of growth, development and health of children, starting from foetal life until adolescence $[29,30]$. Pregnant women, attending one of the participating midwifery practices or antenatal clinics and expected to deliver in Rotterdam, were eligible for the study. Regular health care workers (midwives, obstetricians) informed the women about the study. Most women spoke Dutch, otherwise the study was explained and questionnaires were provided in their native language. Enrolment was scheduled in early pregnancy (gestational age $<18$ weeks) at the first routine foetal ultrasound examination, but was allowed until delivery. Women scheduled for termination of pregnancy and women with a miscarriage or perinatal death prior to or at the first ultrasound were not included. Generation R started in 2002; the Chlamydia sub-study was between February 2003 and January 2005.

\section{Risk factors}

Data were obtained using confidentially administered standardized questionnaires at the time of inclusion. Unanswered questions were registered as missing data. Maternal age was defined as age at enrolment. Ethnicity was defined according to the classification of Statistics Netherlands [30]. Most women were Dutch (49\%), Surinamese (9\%), Turkish
(9\%) or Moroccan (7\%). Educational levels of participating women were defined in groups by highest attained education (primary school, secondary school, higher education). Marital status was defined as married if married or living together in partnership. Further information was obtained regarding gravidity, number of sexual partners in the year prior to pregnancy, history of an STI, and use of cigarettes, alcohol and drugs.

\section{Microbiological diagnosis}

Women provided a first-void urine specimen to test for $C$. trachomatis at enrolment. Urines were stored at $4{ }^{\circ} \mathrm{C}$, transported the same or following working day, and processed within $24 \mathrm{~h}$ of receipt by the laboratory. DNA was isolated from pooled urine specimens using the MagNA Pure LC Bacterial DNA isolation Kit III (Roche Molecular Systems, Alameda, USA) and amplified by polymerase chain reaction (PCR) (Cobas Amplicor, Roche Molecular Diagnostics, Branchburg, USA) [31]. In brief, pools were made of five individual urines by adding $200 \mu \mathrm{l}$ of each urine into one tube. From each pool the full 1,000 $\mu \mathrm{l}$ were taken, and centrifuged for $10 \mathrm{~min}$. Subsequently, $900 \mu \mathrm{l}$ were removed and the pellet was resuspended in $100 \mu \mathrm{l}$ of the remaining supernatant, mixed with $130 \mu \mathrm{l}$ lysis buffer and $20 \mu \mathrm{l}$ proteinase $\mathrm{K}$, incubated for $10 \mathrm{~min}$, and thereafter denatured for $10 \mathrm{~min}$. Finally, DNA was isolated in the automated MagNA Pure LC using a sample volume of $250 \mu \mathrm{l}$ and an elution volume of $100 \mu \mathrm{l}$. Then, $25 \mu \mathrm{l}$ was used for PCR. Urines from positive pools were individually re-tested and reported as negative or positive.

\section{Pregnancy outcomes}

Information about pregnancy outcomes (miscarriage, perinatal death, gestational age, birthweight) was obtained postnatally from midwives and hospital registries. Gestational age was established by foetal ultrasound examination instead of last menstrual period. Establishing gestational age by using the first day of the last menstrual period is not reliable for a variety of reasons including the large number of women who do not know their exact date, have irregular menses or amenorrhoea, use oral contraceptives or bleed in early pregnancy. Establishing gestational age by foetal ultrasound can overcome these problems. Foetal ultrasound was performed by regular health care providers at each prenatal visit, which were planned in early pregnancy (gestational age $<18$ weeks), mid-pregnancy (gestational age 18-25 weeks) and late pregnancy (gestational age $\geq 25$ weeks). The individual time scheme of assessments depended on the specific gestational age at enrolment. Pregnancy dating-curves were derived in a subsample of the Generation $\mathrm{R}$ study cohort including subjects with complete data on both the first day of 
the last menstrual period and crown-rump length or biparietal diameter. Subsequently, gestational age at prenatal enrolment and, as a consequence, at delivery was retrospectively established by crown-rump length or biparietal diameter measured in early pregnancy or mid-pregnancy (30). Preterm birth was defined as delivery at a gestational age of less than 37 weeks, with subgroups of gestational ages less than 32 weeks and less than 35 weeks. Low birthweight was defined as weight below 2,500 g, small for gestational age (SGA) as birthweight less than 2 standard deviation scores (SDSs) below the mean for gestation. Birthweight measurements were converted into gestational age adjusted SDS [32].

Ethical aspects

The $C$. trachomatis study was embedded within the framework of Generation R [29, 30], which were both approved by the Medical Ethical Committee for Research on Human Subjects of the Erasmus MC, Rotterdam. Written informed consent was obtained from all participants. Generation R provided data anonymously.

\section{Data analysis}

Associations of C. trachomatis infection during pregnancy with socio-economic and life style risk factors of women were assessed using multiple logistic regression models. Unequivocal confounders were selected based on previous studies. Associations for each risk factor were studied while adjusting for all other risk factors and the confounders alcohol, drugs and smoking. We imputated missing data in other risk factors and confounders with multiple imputations. Preterm birth was analysed using multiple logistic regression models. We adjusted for maternal age, ethnicity, gravidity, education, and smoking).

The Kaplan-Meier procedure was used to illustrate the proportion of women delivering at given gestational ages and the Breslow test to calculate the significance of the difference between gestational ages at delivery of chlamydia-positive and chlamydia-negative women.

The proportion of preterm delivery attributable to C. trachomatis in women in the total population was assessed using the population attributable fraction of risk (PAR) [33]. The PAR was calculated with the observed relative risk (RR) and the population fraction with chlamydial infection (PF):

$\mathrm{PAR}=[(\mathrm{RR}-1) \mathrm{PF}] /[1+(\mathrm{RR}-1) \mathrm{PF}]$.

Birthweight as a continuous variable was analysed using multiple linear regression models; low birthweight and SGA with multiple logistic regression models. The latter were adjusted for known determinants of low birthweight (maternal age, ethnicity, gravidity), socio-economic status and life style related variables (education, smoking).
Measures of association are presented with $95 \%$ confidence intervals (CI).

Statistical analysis was performed using the Statistical Package of Social Sciences version 11.0 for Windows (SPSS Inc, Chicago, IL, USA). Data imputation was done with the $M I$ procedure in SAS 9.13.

\section{Results}

Population for analysis

During the study period Generation $\mathrm{R}$ enrolled 5,167 pregnant women (Fig. 1), of whom 4,676 women $(90 \%)$ provided a urine sample and were enrolled in the Chlamydia sub-study. Of these, 621 urines could not be matched to the respective questionnaires in the database. Urine samples and data from 4,055 women were analysed for the prevalence and risk factors for $C$. trachomatis infection. Half the women were included within the first 14 weeks of their pregnancy, 95\% within 22 weeks.

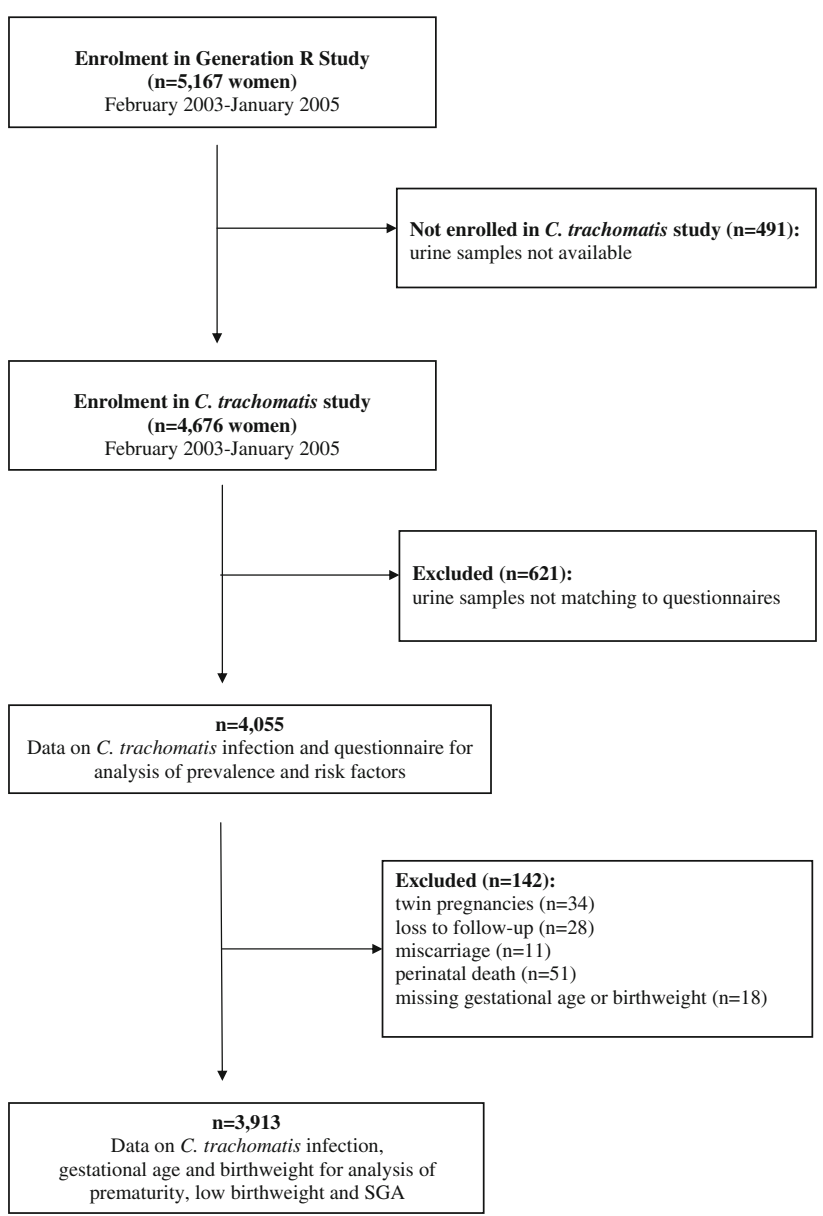

Fig. 1 Profile of the generation $\mathrm{R}$ sub-study on Chlamydia trachomatis 


\section{Prevalence}

Chlamydia trachomatis was detected in 157 of 4,055 (3.9\%) women. Age-specific prevalences were $13.5 \%$ in women age $\leq 20$ years, $6.7 \%$ between 21 and 25 years, $3.3 \%$ between 26 and 30 years and $1.6 \%$ in women over 30 years. Prevalences were highest in Antillean (16.2\%), Cape Verdean $(10.8 \%)$ or Surinamese $(9.1 \%)$ women, and women with low education $(5.8 \%)$, single marital status $(11.9 \%)$, first pregnancies $(4.5 \%)$, multiple sexual partners (7.7\%), or a history of an STI $(6.3 \%)$ (Table 1$)$.

Women with missing data on ethnicity, education and smoking had higher chlamydia rates than women with data recorded: $6.5 \%$ versus $3.6 \%(P=0.01), 6.3 \%$ versus $3.6 \%$
$(P=0.01)$ and $4.8 \%$ versus $3.4 \% \quad(P=0.04)$, respectively. Women with missing data on other variables had not higher rates of chlamydial infection.

\section{Risk factors}

In the unadjusted analysis age below 30 years, Antillean, Cape Verdean and Surinamese ethnicity, education, single marital status, multiple sexual partners and history of an STI were significantly associated with chlamydial infection (Table 1). In the adjusted analysis age below 21 years, Antillean ethnicity and single marital status remained risk factors for infection; other maternal factors were not independently associated. Moroccan or Turkish women had a lower risk.

Table 1 Socio-economic and life style risk factors of Chlamydia trachomatis infection in pregnant women

\begin{tabular}{|c|c|c|c|c|}
\hline \multicolumn{5}{|c|}{ Chlamydia trachomatis infection } \\
\hline Risk factors & $\begin{array}{l}\text { Negative } \\
n=3,898\end{array}$ & $\begin{array}{l}\text { Positive } \\
n=157(\%)\end{array}$ & $\begin{array}{l}\text { Crude } \\
\text { OR }(95 \% \mathrm{CI})\end{array}$ & $\begin{array}{l}\text { Adjusted } \\
\text { OR }(95 \% \mathrm{CI}) \#\end{array}$ \\
\hline \multicolumn{5}{|l|}{ Age groups $(n=4055)$} \\
\hline$<21$ & 217 & $34(13.5)$ & $9.43(5.6-15.8)^{* *}$ & $1.79(1.2-2.6)^{* *}$ \\
\hline $21-25$ & 741 & $53(6.7)$ & $4.31(2.7-6.8)^{* *}$ & $1.29(1.0-1.7)$ \\
\hline $26-30$ & 1194 & $41(3.3)$ & $2.07(1.3-3.4)^{* *}$ & $0.89(0.7,1.2)$ \\
\hline$>30$ & 1746 & $29(1.7)$ & 1.00 & 1.00 \\
\hline \multicolumn{5}{|l|}{ Ethnicity $(n=3730)$} \\
\hline Dutch & 1748 & $33(1.8)$ & 1.00 & 1.00 \\
\hline Cape Verdean & 149 & $18(10.8)$ & $6.40(3.5-11.6)^{* *}$ & $1.54(0.9-2.5)$ \\
\hline Antillean & 109 & $21(16.2)$ & $10.21(5.7-18.2)^{* *}$ & $2.27(1.4-3.7)^{* *}$ \\
\hline Surinamese & 310 & $31(9.1)$ & $5.30(3.2-8.8)^{* *}$ & $1.43(1.0-2.1)$ \\
\hline Moroccan/Turkish & 610 & $14(2.2)$ & $1.22(0.7-2.3)$ & $0.51(0.3-0.9)^{*}$ \\
\hline Other (non-) western & 668 & $19(2.8)$ & $1.51(0.9-2.7)$ & $0.68(0.4-1.1)$ \\
\hline \multicolumn{5}{|l|}{ Education $(n=3656)$} \\
\hline Primary school & 389 & $24(5.8)$ & $3.32(1.9-5.8)^{* *}$ & $1.28(0.9-1.8)$ \\
\hline Secondary school & 1573 & $79(4.8)$ & $2.71(1.8-4.2)^{* *}$ & $0.93(0.7-1.2)$ \\
\hline Higher education & 1,562 & $29(1.8)$ & 1.00 & 1.00 \\
\hline \multicolumn{5}{|c|}{ Marital status $(n=3648)$} \\
\hline Not married & 479 & $65(11.9)$ & $5.88(4.1-8.4)^{* *}$ & $1.60(1.3-2.0)^{* *}$ \\
\hline Married & 3,034 & $70(2.3)$ & 1.00 & 1.00 \\
\hline \multicolumn{5}{|c|}{ Gravidity $>1(n=4011)$} \\
\hline No & 1,719 & $81(4.5)$ & 1.00 & 1.00 \\
\hline Yes & 2,138 & $73(3.3)$ & $0.72(0.5-1.0)$ & $0.85(0.7-1.0)$ \\
\hline \multicolumn{5}{|c|}{ Multiple sexual partners in year prior to pregnancy $(n=3289)$} \\
\hline No & 2,918 & $99(3.3)$ & 1.00 & 1.00 \\
\hline Yes & 251 & $21(7.7)$ & $2.47(1.5-4.0)^{* *}$ & $1.23(0.7-2.2)$ \\
\hline \multicolumn{5}{|c|}{ History of STI $(n=3313)$} \\
\hline No & 2,778 & $100(3.5)$ & 1.00 & 1.00 \\
\hline Yes & 370 & $25(6.3)$ & $1.88(1.2-3.0)^{* *}$ & $1.35(0.7-2.5)$ \\
\hline Do not know & 38 & $2(5.0)$ & $1.46(0.4-6.2)$ & $0.79(0.3-2.2)$ \\
\hline
\end{tabular}

Values are frequencies and odds ratios $(95 \% \mathrm{CI}), * P$-value $<0.05, * * P$-value $<0.01$

\# Adjusted for all other risk factors, use of drugs, alcohol and smoking with multiple imputation of missing data in the other factors 
Pregnancy outcomes

Pregnancy outcomes are shown in Table 2. Of 4,055 pregnancies 3,931 resulted in live singleton births and 34 in live twins. Women who gave birth to twins were more often chlamydia-positive than women who had singletons $(P=0.05)$. Miscarriage $(n=11)$ and perinatal death $(33$ stillbirth, 18 neonatal death) occurred in $1.5 \%$ pregnancies. These adverse events were not associated with chlamydial infection during pregnancy. Preterm delivery occurred in 190 women $(4.9 \%)$ of which prematurity before 32 weeks $(0.6 \%)$ and 35 weeks $(1.6 \%)$ of gestation was significantly associated with chlamydial infection (Table 2). No significant association was observed with low birthweight.

After exclusion of women who were lost to follow up, or who had twin pregnancies, a miscarriage or perinatal death, the effect of Chlamydia on gestational age and birthweight was further analysed for 3,913 women and neonates.

\section{Gestational age}

The distribution of gestational ages according to the maternal chlamydial status is shown in a Kaplan-Meier plot (Fig. 2). Chlamydia-positive women had a significantly shorter duration of gestation $(\mathrm{P}$ Breslow $=0.02)$.

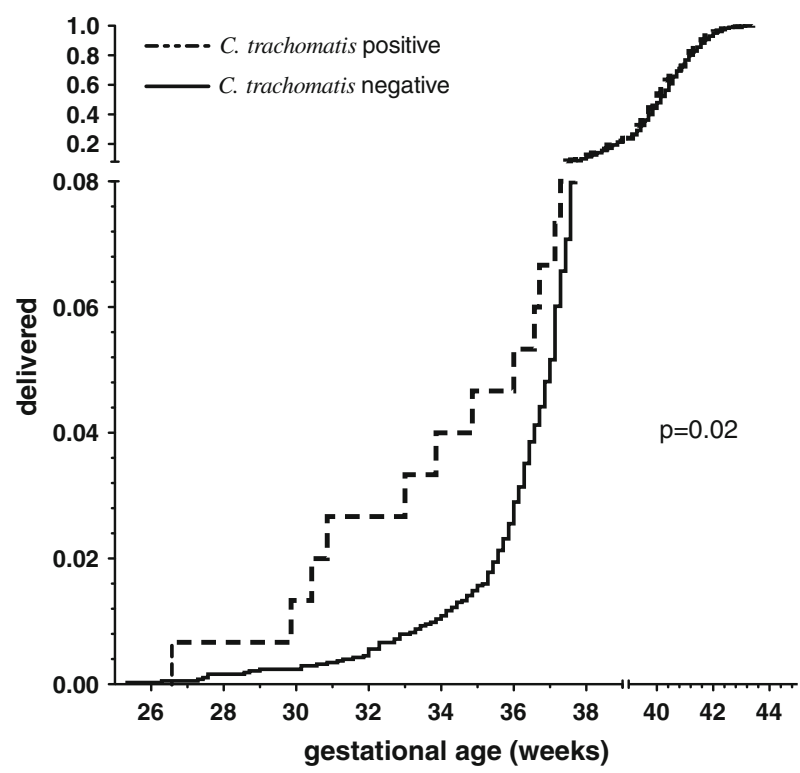

Fig. 2 Kaplan-Meier analysis of duration of gestation at delivery in women with and without Chlamydia trachomatis infection

Unadjusted analysis (Table 3) showed that chlamydiapositive women had a significantly higher risk of preterm delivery before 32 weeks compared to delivery at term (OR 5.69 [95\% CI 1.90, 17.03]). After adjustment for maternal age, ethnicity, education, gravidity, and smoking

Table 2 Pregnancy outcomes of women and their association with Chlamydia trachomatis infection

\begin{tabular}{|c|c|c|c|c|}
\hline \multirow[t]{2}{*}{ Outcomes } & \multicolumn{4}{|c|}{ Chlamydia trachomatis infection } \\
\hline & Negative & Positive & Percentage positive (95\% CI) & $P$-value* \\
\hline \multicolumn{5}{|l|}{ All outcomes $(n=4,055)$} \\
\hline All women enrolled & 3,898 & 157 & $3.9(3.3-4.5)$ & \\
\hline \multicolumn{5}{|c|}{ Live pregnancy outcomes $(n=4,055)$} \\
\hline Live singleton birth & 3,780 & 151 & $3.8(3.2-4.4)$ & 1.0 (reference) \\
\hline Live twin birth & 30 & 4 & $11.8(0.3-21.9)$ & 0.05 \\
\hline Lost to follow up & 26 & 2 & $7.1(0.0-17.3)$ & 0.29 \\
\hline \multicolumn{5}{|l|}{ Adverse pregnancy outcomes } \\
\hline \multicolumn{5}{|l|}{ Demise $(n=4,055)$} \\
\hline Miscarriage & 11 & 0 & 0 & 1.00 \\
\hline Perinatal death & 51 & 0 & 0 & 0.27 \\
\hline \multicolumn{5}{|c|}{ Gestational age ${ }^{* *}(n=3,913)$} \\
\hline Term, $\geq 37$ weeks & 3,583 & 140 & $3.8(3.2-4.4)$ & 1.0 (reference) \\
\hline Prematurity, $<37$ weeks & 180 & 10 & $5.3(2.1-8.5)$ & 0.33 \\
\hline Prematurity, $<35$ weeks & 57 & 7 & $10.9(3.1-18.8)$ & 0.01 \\
\hline Prematurity, $<32$ weeks & 18 & 4 & $18.2(0.7-36.7)$ & 0.01 \\
\hline \multicolumn{5}{|l|}{ Birthweight $* *(n=3,913)$} \\
\hline$\geq 2,500 \mathrm{~g}$ & 3,589 & 140 & $3.8(3.1-4.4)$ & 1.0 (reference) \\
\hline$<2,500 \mathrm{~g}$ & 174 & 10 & $5.4(2.1-8.7)$ & 0.25 \\
\hline
\end{tabular}

* $P$-value (Chi-square or Fishers exact test) for comparison of Chlamydia trachomatis prevalence with respective outcome categories of live singleton birth, gestational age $\geq 37$ weeks, and birthweight $\geq 2,500$ gram

** Including live singleton birth outcomes only 
Table 3 Risk for preterm delivery among women with Chlamydia trachomatis infection

\begin{tabular}{|c|c|c|c|}
\hline & \multicolumn{3}{|c|}{ Risk for preterm delivery } \\
\hline & $\begin{array}{l}<32 \text { weeks } \\
n=22\end{array}$ & $\begin{array}{l}<35 \text { weeks } \\
n=64\end{array}$ & $\begin{array}{l}<37 \text { weeks } \\
n=190\end{array}$ \\
\hline & Unadjusted odds ratio & & \\
\hline \multirow[t]{2}{*}{ C. trachomatis infection } & $5.69(1.9-17.0)^{* *}$ & $3.14(1.4-7.0)^{* *}$ & $1.42(0.7-2.8)$ \\
\hline & Adjusted odds ratio ${ }^{\#}$ & & \\
\hline C. trachomatis infection & $4.35(1.3-15.2)^{*}$ & $2.66(1.1-6.5)^{*}$ & $1.17(0.6-2.4)$ \\
\hline
\end{tabular}

Analyses are done versus delivery $\geq 37$ weeks $(n=3,724)$

\# Adjusted for maternal age, ethnicity, education, gravidity and smoking with multiple imputation

Values are odds ratios $(95 \%$ confidence interval), $* P$-value $<0.05, * * P$-value $<0.01$

a significant four-fold increased risk (OR 4.35 [95\% CI 1.3-15.2]) remained. Chlamydia-positive women also had a significantly higher risk of preterm delivery before 35 weeks (OR 3.14 [95\% CI 1.4-7.0]), which also remained after adjustment for the above-stated confounders (OR 2.66 [95\% CI 1.1-6.5]). Chlamydia-positive women had no increased risk of preterm delivery before 37 weeks.

The fraction of premature deliveries before 32 and 35 weeks gestation attributable to $C$. trachomatis infection in women was $14.9 \%$ (95\% CI 4.5-39.5) and 7.4\% (95\% CI 2.5-20.1), respectively.

\section{Birthweight}

Crude analysis of differences in birthweight (in grams) between neonates born to chlamydia-positive and chlamydia-negative women showed a significant difference (-114 g [95\% CI -206, -23]), which disappeared after adjustment for gestational age, maternal age, ethnicity, education, gravidity and smoking $(-20 \mathrm{~g}[95 \% \mathrm{CI}-98$, 58]). A comparison of low birthweight $(n=184)$ between the two groups also showed no significant difference (unadjusted OR 1.47 [95\% CI 0.8-2.8]; adjusted OR 0.95, [0.4-2.2]). Analysis of the correlation between birthweight, expressed in SDSs, of neonates and their gestational ages according to the maternal chlamydial status is demonstrated in Fig. 3. This figure suggests that neonates born to chlamydia-positive women had, on average, a lower birthweight SDS, especially when prematurely born. However, the difference did not reach statistical significance; also not after stratification by gestational ages (Table 4). Furthermore, neonates born to chlamydia-positive women were not more often SGA than neonates born to chlamydia-negative women, $3.3 \%$ versus $3.6 \%(P=0.88)$.

\section{Discussion}

This study provides evidence that $C$. trachomatis infection during pregnancy is associated with preterm delivery, but not with low birthweight or being small for gestational age. Young age, Antillean ethnicity and single marital status were independent risk factors for $C$. trachomatis infection in pregnant women.

The strength of this study is its population-based, noninterventional and prospective design with a large number of well-described participants, adjustments for many potential confounders, use of a highly sensitive microbiological test method and near perfect follow-up until delivery $(97 \%)$.

A potential weakness is that the Generation $\mathrm{R}$ cohort is slightly skewed towards a relatively affluent, healthy study population [30]. However, we do not expect this to affect our results since the study was designed to assess the effects of Chlamydia on pregnancy outcomes in a nonhospital based, low-risk population. Another weakness could be that not all women initially enrolled in the overall study could be tested for $C$. trachomatis. We had a nonresponse of $9.5 \%$ (491 women) for the Chlamydia study. This may in part be true non-response, but is more likely due to a change in the Generation $\mathrm{R}$ routine with a later start of inclusion of urine collections for the Chlamydia study. Another $12.0 \%$ (621 women) had to be excluded because their urines could not be matched to the respective questionnaires in the database. This was due to logistical problems in the pilot phase of the Chlamydia study. However, all risk factors were similarly distributed among tested and untested women and no differences were found in median gestational age and mean birthweight (39.8 weeks versus 39.8 weeks; $P=0.84,3,408$ g versus $3,407 \mathrm{~g} ; \quad P=0.92$ ). Likewise, no differences were observed between chlamydia-positive and negative women regarding the measurement and calculation of gestational age at the prenatal visits. Furthermore, our numbers were too small to assess an association of Chlamydia with miscarriage or perinatal death. Of all enrolled women with C. trachomatis results, $62(1.5 \%)$ had a miscarriage or perinatal death. Data on gestational age and birthweight were not available for these deliveries, but likely is that 


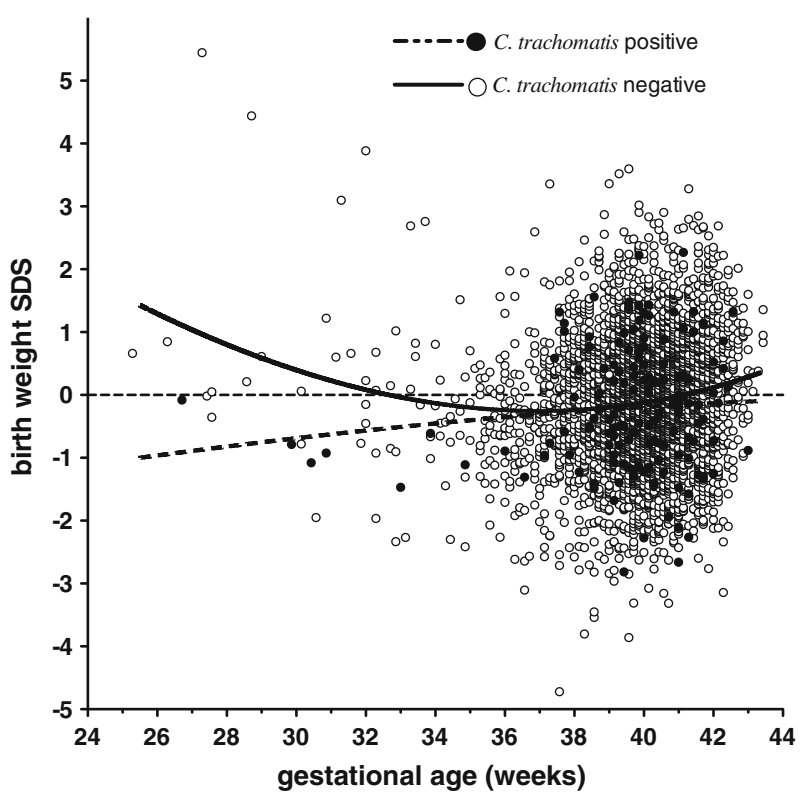

Fig. 3 Birthweight standard deviation scores (SDS) versus gestational ages of neonates born to women with and without Chlamydia trachomatis infection

these women delivered relatively more often prematurely. None of these women tested positive for $C$. trachomatis. Theoretically, our effect estimates for associations of chlamydial infection with gestational age and birthweight could be biased and exaggerated when these associations would differ between all fetuses and fetal 'survivors'. This would be the case if $C$. trachomatis infection would have a 'protective' effect on early fetal death. However, this is most unlikely $[8,20]$.
Previous studies of associations between maternal chlamydial infection and subsequent spontaneous preterm delivery produced mixed results. Most of these studies were small compared to our study (less than 1,000 women included) and were published 10 to over 20 years ago. Early studies were often based on serology, which does not reliably distinguish current from past infection $[9,11,14$, 15]. One case-control study found an association between the presence of IgM anti-chlamydial antibody and preterm delivery [11]. Studies using cervical culture for C. trachomatis at that time also yielded conflicting results $[9,10$, 13, 14]. More recently, sensitive DNA amplification techniques have been used to screen pregnant women for C. trachomatis, but again with contradicting results regarding preterm delivery $[21-24,34,35]$. Using this methodology one case-control study, nested in a USA study among 2,929 pregnant women, reported a two- to three-fold increased risk of preterm delivery before 35 weeks gestation [21]. Later, the same group reported from an observational study among 2,470 women with bacterial vaginosis or Trichomonas vaginalis infection enrolled in a multicentre randomized antibiotic treatment trial that Chlamydia in midterm pregnancy was not associated with increased risk of preterm delivery [23]. However, most of their chlamydia-positive women were treated between 16-29 weeks gestation. Three more studies in which chlamydia-positive pregnant women were treated also found no association with prematurity or a much lower relative risk for prematurity (1.50) than we found in our study [24, 34, 35]. In a prospective South-African study among low-risk pregnant women, chlamydia-positive

Table 4 Differences in birthweight between neonates born to women with and without Chlamydia trachomatis infection

\begin{tabular}{|c|c|c|c|c|}
\hline & \multirow[t]{2}{*}{ Number $(\%)$} & \multirow[t]{2}{*}{ Mean birth weight SDS } & \multicolumn{2}{|c|}{ Difference in birthweight SDS* } \\
\hline & & & Unadjusted & Adjusted $^{\#}$ \\
\hline \multicolumn{5}{|l|}{ Gestational age } \\
\hline \multicolumn{5}{|c|}{$<32$ weeks $(n=22)$} \\
\hline C. trachomatis - & $18(82)$ & 0.83 & & \\
\hline C. trachomatis + & $4(18)$ & -0.72 & $-1.54(-3.6-0.5)$ & $-1.43(-4.6-1.7)$ \\
\hline \multicolumn{5}{|c|}{$<35$ weeks $(n=64)$} \\
\hline C. trachomatis - & $57(89)$ & 0.13 & & \\
\hline C. trachomatis + & $7(11)$ & -0.87 & $-0.99(-2.2-0.2)$ & $-0.79(-2.2-0.7)$ \\
\hline \multicolumn{5}{|c|}{$<37$ weeks $(n=190)$} \\
\hline C. trachomatis - & $180(95)$ & -0.26 & & \\
\hline C. trachomatis + & $10(5)$ & -0.85 & $-0.59(-1.4-0.2)$ & $-0.38(-1.2-0.4)$ \\
\hline \multicolumn{5}{|c|}{$\geq 37$ weeks $(n=3,723)$} \\
\hline C. trachomatis - & $3,583(96)$ & -0.08 & & \\
\hline C. trachomatis + & $140(4)$ & -0.19 & $-0.10(-0.3-0.1)$ & $-0.12(-0.1-0.3)$ \\
\hline
\end{tabular}

SDS standard deviation score

\# Adjusted for maternal age, ethnicity, education, gravidity and smoking

Difference and $95 \%$ confidence interval calculated with linear regression analysis 
women (cases, $n=40$ ) had a relative risk of 2.20 for preterm delivery before 37 weeks gestation (controls, $n=303$ ) [22]. In this study women were also tested for Syphilis, Gonorrhoea and bacterial vaginosis, which were found not to be associated with preterm delivery. Likewise, one of the former studies also found no association between preterm delivery and syphilis, bacterial vaginosis, Trichomonas vaginalis and Neisseria gonorrhoeae infection [35]. The true effect of $C$. trachomatis on pregnancy outcomes therefore cannot be fully ascertained from studies in which pregnant women are screened for Chlamydia and treated in the first phases of their pregnancy. In contrast, our study is prospective, non-interventional and population-based ( $n=4,055$ ), which makes that our findings better estimate the effect of Chlamydia on pregnancy and are more representative for the population as a whole.

Preterm birth represents a major problem for obstetrics and neonatology due to its increasing frequency and accompanying socio-economic impact. We found chlamydial infection to be associated with preterm delivery before 32 and 35 weeks gestation, which was much stronger for the former indicating that Chlamydia contributes relatively more to early than late prematurity. For such an important issue, a four-fold increased risk of preterm delivery before 32 weeks gestation implies that a considerable proportion ( $14.9 \%$ in our cohort) of preterm deliveries before 32 weeks gestation is attributable to chlamydial infection in pregnancy. Despite a considerable confidence interval around the estimate, this would classify $C$. trachomatis among the important infective risk factors of early prematurity. The attributable fraction remained significant $(7.4 \%)$ for preterm delivery before 35 weeks. It should be noted, however, that the number and proportion of premature deliveries attributable to Chlamydia highly depends upon the C. trachomatis prevalence in a given population, and that some residual confounding as a result of co-infection by other genitourinary pathogens cannot be excluded. Another limitation could be that we did not correct for other potential risk factors as previous preterm delivery, since we did not have such data, and previous termination of pregnancy in these women since this potential confounder was only recently established [36]. Importantly, we had no information concerning the use of (macrolide) antibiotics during pregnancy, but suggest that this would mitigate, rather than exaggerate, the effect of Chlamydia on pregnancy outcome. The latter information would have been interesting since early treatment may prevent preterm birth $(34,35)$. Finally, pregnant women are not routinely tested and treated for Ureaplasma urealyticum or Mycoplasma genitalium in the Netherlands and neither are women with premature rupture of the membranes routinely treated with antibiotics.

Extrapolation of our findings to the Netherlands, where approximately 3,000 neonates are born before 32 weeks gestation annually [37], showed that $C$. trachomatis infection in pregnancy contributes approximately 450 cases to this burden; for deliveries before 35 weeks gestation these numbers are 7,100 and 525, respectively. Our finding of an association between $C$. trachomatis infection and premature delivery may be useful in a cost-benefit analysis of Chlamydia screening during pregnancy.

Interestingly, $C$. trachomatis infection was more prevalent among women who had twins than those who had singletons, a finding not reported before. Since Chlamydia is associated with infertility and assisted conception for infertility is associated with twin pregnancies, an explanation for our findings may be that chlamydia-positive women were not treated effectively during their infertility work-up or that they were reinfected. This observation warrants further study into medical histories of women with twin deliveries versus women with singletons.

The major risk factors we found are amongst the many previously described including young age, urban residence, low socio-economic class, specific ethnic groups, single marital status and recent changes in sexual partnerships or sexual promiscuity [9, 26, 38, 39]. Adolescents are at highest risk of infection, which was also observed in this study [27]. We could not evaluate urban residence since all participating women resided in Rotterdam. The risk factors we found are similar to those reported in another Dutch community-based study [28, 40]. Importantly, C. trachomatis prevalences vary widely [26], which will directly affect the incidence of complications attributable to this infection, including preterm delivery.

One may question the design of our study since women screened and found positive for $C$. trachomatis were not treated. The design of our study would face ethical barriers in countries that have national guidelines or directives advocating Chlamydia screening and treatment in the routine of antenatal care, and would be impossible to perform [41, 42]. However, in most countries of the European Union, including the Netherlands, screening and treatment for Chlamydia during pregnancy remains controversial and is currently not recommended in routine antenatal care $[43,44]$. Our study provides novel data that may well have an impact on the future antenatal screening strategy in the Netherlands and elsewhere. In addition, Generation R was designed as a non-interventional followup study [29, 30]. All following substudies, including ours, had to fit into this overall design. Furthermore, Generation $\mathrm{R}$ provided the data anonymously to protect the privacy of participants. We, therefore, had no access to names or addresses of chlamydia-positive women.

In conclusion, $C$. trachomatis urogenital infection in pregnant women increases the risk of preterm delivery, especially early prematurity, such that a significant proportion of preterm deliveries can be attributed to this 
infection. In order to improve birth outcomes, health systems should consider additional focus on $C$. trachomatis infection, especially in young women and others at increased risk.

Acknowledgments We thank all participants and collaborators in the Generation R Study. The Generation R Study is conducted by the Erasmus University Medical Centre, Rotterdam, in collaboration with the School of Law and Faculty of Social Sciences of the Erasmus University Rotterdam, the Municipal Health Service Rotterdam area, the Rotterdam Homecare Foundation and the Stichting Trombosedienst and Artsenlaboratorium Rijnmond (STAR), Rotterdam. We gratefully acknowledge the contribution of general practitioners, hospitals, midwives and pharmacies in Rotterdam. The first phase of the study is made possible by financial support from the Erasmus University Medical Centre, Rotterdam, the Erasmus University Rotterdam and the Netherlands Organization for Health Research and Development (ZonMw). The authors do not have an association that might pose a conflict of interest.

Open Access This article is distributed under the terms of the Creative Commons Attribution Noncommercial License which permits any noncommercial use, distribution, and reproduction in any medium, provided the original author(s) and source are credited.

\section{References}

1. Mardh PA. Influence of infection with Chlamydia trachomatis on pregnancy outcome, infant health and life-long sequelae in infected offspring. Best Pract Res Clin Obstet Gynaecol. 2002; 16(6):847-64.

2. Wiesenfeld HC, Hillier SL, Krohn MA, Amortegui AJ, Heine RP, Landers DV, et al. Lower genital tract infection and endometritis: insight into subclinical pelvic inflammatory disease. Obstet Gynecol. 2002;100(3):456-63.

3. Peipert JF. Clinical practice. Genital chlamydial infections. N Engl J Med. 2003;349(25):2424-30.

4. Manavi K. A review on infection with Chlamydia trachomatis. Best Pract Res Clin Obstet Gynaecol. 2006;20(6):941-51.

5. Darville T. Chlamydia trachomatis infections in neonates and young children. Semin Pediatr Infect Dis. 2005;16(4):235-44.

6. Rours GIJG, Hammerschlag MR, Ott A, De Faber TJ, Verbrugh HA, de Groot R, et al. Chlamydia trachomatis as a cause of neonatal conjunctivitis in Dutch infants. Pediatrics. 2008;121(2):e321-6.

7. Rours GIJG, Hammerschlag MR, Van Doornum GJ, Hop WC, de Groot R, Willemse HF, et al. Chlamydia trachomatis respiratory infection in Dutch infants. Arch Dis Child. 2009;94(9):705-7.

8. Martin DH, Koutsky L, Eschenbach DA, Daling JR, Alexander ER, Benedetti JK, et al. Prematurity and perinatal mortality in pregnancies complicated by maternal Chlamydia trachomatis infections. JAMA. 1982;247(11):1585-8.

9. Harrison HR, Alexander ER, Weinstein L, Lewis M, Nash M, Sim DA. Cervical Chlamydia trachomatis and mycoplasmal infections in pregnancy. Epidemiology and outcomes. JAMA. 1983;250(13):1721-7.

10. Gravett MG, Nelson HP, DeRouen T, Critchlow C, Eschenbach DA, Holmes KK. Independent associations of bacterial vaginosis and Chlamydia trachomatis infection with adverse pregnancy outcome. JAMA. 1986;256(14):1899-903.

11. Sweet RL, Landers DV, Walker C, Schachter J. Chlamydia trachomatis infection and pregnancy outcome. Am J Obstet Gynecol. 1987;156(4):824-33.
12. Alger LS, Lovchik JC, Hebel JR, Blackmon LR, Crenshaw MC. The association of Chlamydia trachomatis, Neisseria gonorrhoeae, and group B streptococci with preterm rupture of the membranes and pregnancy outcome. Am J Obstet Gynecol. 1988;159(2):397-404.

13. Association of Chlamydia trachomatis and Mycoplasma hominis with intrauterine growth retardation and preterm delivery. The John Hopkins Study of Cervicitis and Adverse Pregnancy Outcome. Am J Epidemiol. 1989;129(6):1247-57.

14. Ngassa PC, Egbe JA. Maternal genital Chlamydia trachomatis infection and the risk of preterm labor. Int J Gynaecol Obstet. 1994;47(3):241-6.

15. Claman P, Toye B, Peeling RW, Jessamine P, Belcher J. Serologic evidence of Chlamydia trachomatis infection and risk of preterm birth. CMAJ. 1995;153(3):259-62.

16. Nadisauskiene R, Bergstrom S, Stankeviciene I, Spukaite T. Endocervical pathogens in women with preterm and term labour. Gynecol Obstet Invest. 1995;40(3):179-82.

17. Martin DH, Eschenbach DA, Cotch MF, Nugent RP, Rao AV, Klebanoff MA, et al. Double-blind placebo-controlled treatment trial of Chlamydia trachomatis endocervical infections in pregnant women. Infect Dis Obstet Gynecol. 1997;5(1):10-7.

18. Kovacs L, Nagy E, Berbik I, Meszaros G, Deak J, Nyari T. The frequency and the role of Chlamydia trachomatis infection in premature labor. Int J Gynaecol Obstet. 1998;62(1):47-54.

19. Rastogi S, Kapur S, Salhan S, Mittal A. Chlamydia trachomatis infection in pregnancy: risk factor for an adverse outcome. Br J Biomed Sci. 1999;56(2):94-8.

20. Gencay M, Koskiniemi M, Ammala P, Fellman V, Narvanen A, Wahlstrom $\mathrm{T}$, et al. Chlamydia trachomatis seropositivity is associated both with stillbirth and preterm delivery. APMIS. 2000;108(9):584-8.

21. Andrews WW, Goldenberg RL, Mercer B, Iams J, Meis $P$, Moawad A, et al. The preterm prediction study: association of second-trimester genitourinary chlamydia infection with subsequent spontaneous preterm birth. Am J Obstet Gynecol. 2000; 183(3):662-8.

22. Odendaal HJ, Schoeman J. The association between Chlamydia trachomatis genital infection and spontaneous preterm labour. S. Afr J Obstet Gynaecol. 2006;12(3):146-9.

23. Andrews WW, Klebanoff MA, Thom EA, Hauth JC, Carey JC, Meis PJ, et al. Midpregnancy genitourinary tract infection with Chlamydia trachomatis: association with subsequent preterm delivery in women with bacterial vaginosis and Trichomonas vaginalis. Am J Obstet Gynecol. 2006;194(2):493-500.

24. Blas MM, Canchihuaman FA, Alva IE, Hawes SE. Pregnancy outcomes in women infected with Chlamydia trachomatis: a population-based cohort study in Washington State. Sex Transm Infect. 2007;83(4):314-8.

25. Wilson JS, Honey E, Templeton A, Paavonen J, Mardh PA, Stray-Pedersen B. A systematic review of the prevalence of Chlamydia trachomatis among European women. Hum Reprod Update. 2002;8(4):385-94.

26. Smith JR, Taylor-Robinson D. Infection due to Chlamydia trachomatis in pregnancy and the newborn. Baillieres Clin Obstet Gynaecol. 1993;7(1):237-55.

27. Adams EJ, Charlett A, Edmunds WJ, Hughes G. Chlamydia trachomatis in the United Kingdom: a systematic review and analysis of prevalence studies. Sex Transm Infect. 2004;80(5): 354-62.

28. van Bergen J, Gotz HM, Richardus JH, Hoebe CJ, Broer J, Coenen AJ. Prevalence of urogenital Chlamydia trachomatis increases significantly with level of urbanisation and suggests targeted screening approaches: results from the first national population based study in the Netherlands. Sex Transm Infect. 2005;81(1):17-23. 
29. Jaddoe VW, Bakker R, van Duijn CM, van der Heijden AJ, Lindemans J, Mackenbach JP, et al. The generation $r$ study biobank: a resource for epidemiological studies in children and their parents. Eur J Epidemiol. 2007;22(12):917-23.

30. Jaddoe VW, van Duijn CM, van der Heijden AJ, Mackenbach JP, Moll HA, Steegers EA, et al. The generation R study: design and cohort update 2010. Eur J Epidemiol. 2010;25(11):823-41.

31. Rours GIJG, Verkooyen RP, Willemse HF, van der Zwaan EA, van Belkum A, de Groot R, et al. Use of pooled urine samples and automated DNA isolation to achieve improved sensitivity and cost-effectiveness of large-scale testing for Chlamydia trachomatis in pregnant women. J Clin Microbiol. 2005;43(9):4684-90.

32. Niklasson AEA, Fryer JG, Karlberg J, Lawrence C, Karlberg P. An update of the Swedish reference standards for weight, length and head circumference at birth for given gestational age (1977-1981). Acta Paediatr Scand. 1991;80(8-9):756-62.

33. Rothman K.J. GS. Modern epidemiology. second ed: LippincottRaven 1998.

34. Kataoka S, Yamada T, Chou K, Nishida R, Morikawa M, Minami $\mathrm{M}$, et al. Association between preterm birth and vaginal colonization by mycoplasmas in early pregnancy. J Clin Microbiol. 2006;44(1):51-5.

35. Silveira MF, Ghanem KG, Erbelding EJ, Burke AE, Johnson HL, Singh RH, et al. Chlamydia trachomatis infection during pregnancy and the risk of preterm birth: a case-control study. Int $\mathbf{J}$ STD AIDS. 2009;20(7):465-9.

36. Moreau C, Kaminski M, Ancel PY, Bouyer J, Escande B, Thiriez $\mathrm{G}$, et al. Previous induced abortions and the risk of very preterm delivery: results of the EPIPAGE study. BJOG. 2005;112(4): 430-7.

37. The Netherlands Perinatal Registry. Perinatal Care in the Netherlands 2003. Bilthoven: Stichting Perinatale Registratie; 2006.

38. Thomas AG, Brodine SK, Shaffer R, Shafer MA, Boyer CB, Putnam S, et al. Chlamydial infection and unplanned pregnancy in women with ready access to health care. Obstet Gynecol. 2001;98(6):1117-23.

39. Chen MY, Fairley CK, De Guingand D, Hocking JS, Tabrizi S, Wallace EM, et al. Screening pregnant women for chlamydia: what are the predictors of infection? Sex Transm Infect. 2008; 85(1):31-5.

40. Gotz HM, van Bergen JE, Veldhuijzen IK, Broer J, Hoebe CJ, Steyerberg EW, et al. A prediction rule for selective screening of Chlamydia trachomatis infection. Sex Transm Infect. 2005; 81(1):24-30.

41. Centers for Disease Control and Prevention. Sexually transmitted diseases treatment guidelines. MMWR Recomm Rep 2006;55 (RR-11):1-94.

42. U.S. Preventive Services Task Force. Screening for Chlamydial infection: U.S. preventive services task force recommendation statement. Ann Intern Med. 2007;147(2):128-34.

43. Bernloehr A, Smith P, Vydelingum V. Antenatal care in the European Union: a survey on guidelines in all 25 member states of the Community. Eur J Obstet Gynecol Reprod Biol. 2005; 122(1):22-32.

44. Health Council of the Netherlands. Screening for Chlamydia, nr 2004/07. 2004:1-106. 